\title{
Development of a Bioactive Food Additive for Controlling of Fungal Growth
}

Mauricio V. Cruz ${ }^{1,2}$, Marcos A. Pereira-Junior ${ }^{2}$, Karla A. Batista ${ }^{2,3}$, Kátia F. Fernandes ${ }^{2 *}$

${ }^{1}$ Departamento de Áreas Acadêmicas, Instituto Federal de Educação, Ciência e Tecnologia de Goiás, CEP 76400-000, Uruaçu, GO, Brasil.

${ }^{2}$ Departamento de Bioquímica e Biologia Molecular, Laboratório de Química de Polímeros, Universidade Federal de Goiás, CEP 74001-970, Goiânia, GO, Brasil.

${ }^{3}$ Departamento de Áreas Acadêmicas, Instituto Federal de Educação, Ciência e Tecnologia de Goiás, Câmpus Goiânia Oeste, CEP 74270-040, Goiânia, GO, Brasil.

\begin{abstract}
Fresh foods have a great importance in human nutrition. However, they are marketed with greatly reduced shelf life mainly due to fungal spoilage. In this work, cell wall degrading enzymes produced by Trichoderma asperellum TOO (TCWDE) were immobilized onto cashew gum polysaccharide (CGP) in order to evaluate the potential use of this material as food additive aiming to increase the shelf life by inhibiting fungal growth. Results from factorial design $\left(3^{2}\right)$ evidenced that the best conditions for TCWDE immobilization was achieved with 20 min of reaction using $1 \mathrm{mmol} \mathrm{L}^{-1}$ of $\mathrm{NaIO}_{4}$. On these conditions it was observed $91 \%$ of retention yield for NAGase (30.1 $\left.\pm 0.38 \mathrm{U} \mathrm{mL}^{-1}\right), 41 \%$ for chitinase $\left(0.67 \pm 0.05 U \mathrm{~mL}^{-1}\right)$, and $24 \%$ for $\beta$-1,3glucanase $\left(0.017 \pm 0.001 U \mathrm{~mL}^{-1}\right)$. CGP/TCWDE was effective for growth inhibition of Aspergillus fumigatus and Penicillium sp. and the inhibition mechanism seems to involve changes in the cell wall of those microorganisms. Finally, the CGP/TCWDE presented high stability after drying, maintaining enzymatic and biological activity after 200 days of storage at room temperature $\left(25^{\circ} \mathrm{C}\right)$.
\end{abstract}

Keywords-Cashew gum polysaccharide; cell wall degrading enzymes; shelf-life; Trichoderma asperellum; immobilization.

\section{INTRODUCTION}

A total of 805 million people in 2012-2014 were estimated to be suffering from chronic hunger, or not regularly getting enough food to conduct an active life (Koizumi, 2015). On the other hand, according to FAO et al., (2014), roughly one-third of global food produced for human consumption is lost or wasted, because their quality has dropped below an acceptance limit, which amounted in 2011 about 1.3 billion tons (Jedermann et al., 2014).

Considering the increasing trend of the world population growth, this is unacceptable. If at one side of the problem, food production must clearly increase significantly to meet the future demands of an increasing world population, food losses must be greatly reduced, since they also represent a squander of resources used in food production, such as land, water, energy and inputs (FAO et al., 2014).

Additionally, food safety is a major concern all over the world, mainly in developing countries (Grace, 2015). Fresh products like fruits and vegetables are frequently spoiled, especially in countries with tropical and subtropical climate (FAO, 2011). Some plant pathogens start the spoilage in the field while others just proliferate and cause substantial spoilage after harvesting, significantly reducing the shelf life of fresh foods (Rembiałkowska, 2007; Shafie and Rennie, 2012).

Several alternatives for controlling post-harvest microbial spoilage have been currently used, such as careful culling, storage at low temperatures or under controlled atmospheres and application of fungicides (Tournas and Katsoudas, 2005). However, temperature and atmosphere controls are expensive and the consumer concerns about extensive use of fungicides are important factors that limit the use of these methods.

In this sense, studies of the food industry have been directed to the achievement of technologies to improve the shelf life of fresh foods, including bioactive packaging development (Lopez-Rubio et al., 2006; Min et al., 2017), handling improvement in the processing chain, or addition of an agent able to promote the conservation and sanitization of foods during storage (López de Lacey et al., 2012; Olmedo et al., 2017).

Several polysaccharides have been studied for the production of polymer matrices with applications in many areas of biotechnology, including cashew gum polysaccharide (CGP) (Moreira et al., 2015; Silva et al., 2012, 2016, 2010). Cashew gum polysaccharide (CGP) is a complex branched heteropolysaccharide present in the exudate of Anacardium occidentale tree. This edible material has a potential use as water-soluble support for enzyme immobilization as demonstrated by Silva et al., 
(2010). Subsequently, cell wall degrading enzymes produced by Trichoderma asperellum T00 (TCWDE) grown in the presence of crude chitin were immobilized in CGP-based films (Silva et al., 2012). These films were shown to be effective for food preservation avoiding fungi development. However, CGP based films were opaque, which could limit their applications as bioactive packaging due to low consumer acceptance (Silva et al., 2011).

Thus, the objective of this work was to immobilize TCWDE produced by $T$. asperellum directly onto CGP in order to evaluate the potential use of this water-soluble powder as a food additive to increase the shelf life of fresh foods by controlling fungal growth.

\section{MATERIALS AND METHOD}

\subsection{Strain origin and culture conditions}

T. asperellum (strain T00) was obtained from the Laboratório de Química de Polímeros culture collection at the Universidade Federal de Goiás (UFG) and maintained in potato-dextrose-agar medium (PDA), at room temperature. For preparation of inoculum, T. asperellum ( $1 \times 10^{7}$ spores $\mathrm{mL}^{-1}$ of culture medium) was grown in $250 \mathrm{~mL}$ of TLE liquid medium [0.1\% bactopeptone; $0.03 \%$ urea; $0.2 \% \quad \mathrm{KH}_{2} \mathrm{PO}_{4} ; 0.14 \%\left(\mathrm{NH}_{4}\right)_{2} \mathrm{SO}_{4} ; 0.03 \%$ $\mathrm{MgSO}_{4} 7 \mathrm{H}_{2} \mathrm{O} ; 0.03 \% \mathrm{CaCl}_{2} 6 \mathrm{H}_{2} \mathrm{O} ; 1 \mathrm{~mL}$ of $0.01 \%$ trace elements solution $\left(\mathrm{Fe}^{2+}, \mathrm{Mn}^{2+}, \mathrm{Zn}^{2+}\right.$, and $\left.\mathrm{Co}^{2+}\right), 0.1 \%$ glucose], under shaking $(180 \mathrm{rpm})$ at $28^{\circ} \mathrm{C}$ for $72 \mathrm{~h}$.

Penicillium sp. and Aspergillus fumigatus were obtained from Laboratório de Química de Polímeros collection of the UFG and were maintained in PDA medium, at room temperature $\left(25^{\circ} \mathrm{C}\right)$.

\subsection{Conditions for TCWDE induction and production}

For the TCWDE induction experiments, T. asperellum spores were transferred to an Eppendorf flask and then washed with sterile $0.9 \%(\mathrm{w} / \mathrm{v}) \mathrm{NaCl}$ solution. The spores $\left(1 \times 10^{7}\right.$ spores $\mathrm{mL}^{-1}$ ) were transferred to $1000 \mathrm{~mL}$ Erlenmeyer flasks containing $250 \mathrm{~mL}$ of TLE medium, $0.02 \%(\mathrm{w} / \mathrm{v})$ glucose and $0.5 \%(\mathrm{w} / \mathrm{v})$ chitin. The culture was incubated in a rotary shaker $(180 \mathrm{rpm})$, at $28^{\circ} \mathrm{C}$, for 6 days and harvested by filtration with Whatman $\mathrm{n}^{\circ} 1$ filter paper. The culture filtrate containing TCWDE was dialyzed against water, using a cellulose acetate membrane with a molecular weight cut-off at $10 \mathrm{kDa}$, frozen at $-80^{\circ} \mathrm{C}$ and lyophilized. TCWDE powder was stored at room temperature until use for the immobilization tests.

\subsection{Cashew gum polysaccharide (CGP)}

Samples of cashew gum were collected from trees at Aquirás, Ceará, Brazil. Nodules were milled, immersed in distilled water in a proportion of $20 \%(\mathrm{w} / \mathrm{v})$ and kept at room temperature $\left(25^{\circ} \mathrm{C}\right)$, for $24 \mathrm{~h}$, under stirring. The solution was filtered to remove fragments of bark and then precipitated with cold ethanol, in the proportion of 1:3 (v/v), for $24 \mathrm{~h}$. The precipitated CGP was separated by centrifugation, washed with ethanol and dried at room temperature. The white pellets obtained were milled and stored at room temperature in airtight vials.

\subsection{TCWDE immobilization}

Covalent immobilization of TCWDE onto CGP was carried out by mixing $100 \mu \mathrm{L}$ of a TCDWE solution ( 5 $\mathrm{mg} \mathrm{mL} \mathrm{m}^{-1}$ ) with $5 \mathrm{mg} \mathrm{mL}^{-1}$ of CGP solution and $400 \mu \mathrm{L}$ sodium periodate solution. After immobilization, the CGP/TCWDE was precipitated by adding ethanol in a ratio of $3: 1(\mathrm{v} / \mathrm{v})$. The precipitated CGP/TCWDE was separated by centrifugation at $6700 \mathrm{~g}$ for $5 \mathrm{~min}$, dried and stored at room temperature $\left(25^{\circ} \mathrm{C}\right)$ in airtight vials. In order to select the most appropriate combination of sodium periodate concentration and immobilization time a three-level full factorial design $\left(3^{2}\right)$ was carried. For the factorial design, these two variables were confined in three levels: $1 \mathrm{mmol} \mathrm{L}^{-1}$ (low level), $10 \mathrm{mmol} \mathrm{L}^{-1}$ (central level) and $100 \mathrm{mmol} \mathrm{L}^{-1}$ (high level) for sodium metaperiodate concentration and $20 \mathrm{~min}$ (low level), 40 min (central level) and $60 \mathrm{~min}$ (high level) for immobilization time, as shown in Table 1.

\subsection{TCWDE Activity Assays}

\subsubsection{N-Acetylglucosaminidase Activity}

$\mathrm{N}$-Acetylglucosaminidase (NAGase) activity was assayed by monitoring the rate of formation of $p$-nitrophenol from $p$-nitrophenol- $\beta-\mathrm{N}$-acetylglucosamine according to the method of Yabuki et al., (1986). The reaction mixture was composed of $50 \mu \mathrm{L}$ of the TCWDE solution, $100 \mu \mathrm{L}$ of $5.0 \mathrm{mmol} \mathrm{L}^{-1}$ substrate, and $350 \mu \mathrm{L}$ of $50 \mathrm{mmol} \mathrm{L}^{-1}$ sodium acetate buffer of $\mathrm{pH}$ 5.0. After $10 \mathrm{~min}$ of incubation at $37{ }^{\circ} \mathrm{C}, 1.0 \mathrm{~mL}$ of $0.5 \mathrm{~mol} \mathrm{~L}^{-1} \mathrm{Na}_{2} \mathrm{CO}_{3}$ was added to stop the reaction. The amount of released $p$ nitrophenol was spectrophotometrically measured at 405 $\mathrm{nm}$. One unit of enzyme activity (U) was defined as the amount of enzyme that releases $1 \mu \mathrm{mol}$ of $p$-nitrophenol $\mathrm{min}^{-1}$ at $37{ }^{\circ} \mathrm{C}$. Assays of immobilized CGP/TCWDE were done similarly, except the enzyme solution was replaced by $10 \mathrm{mg}$ of CGP/TCWDE. Blank reactions were performed in the presence of CGP activated by sodium periodate $\left(1 \mathrm{mmol} \mathrm{L}^{-1}, 20 \mathrm{~min}\right)$ in absence of enzyme.

\subsection{2 $\beta$-1,3-Glucanase Activity}

$\beta-1,3$-Glucanase activity was evaluated as described by Noronha and Ulhoa, (2000). The reaction assay was performed by mixing $50 \mu \mathrm{L}$ of TCWDE solution with 100 $\mu \mathrm{L}$ of $50 \mathrm{mmol} \mathrm{L}^{-1}$ acetate buffer ( $\mathrm{pH} 5.0$ ), containing 
$0.25 \%$ (w/v) laminarin (Sigma Aldrich, USA). The mixture was incubated at $40{ }^{\circ} \mathrm{C}$ for $30 \mathrm{~min}$, and the reducing sugar produced was determined by the method described by (Miller, 1959). One unit of $\beta-1,3$-glucanase activity (U) was defined as the amount of enzyme that produced $1.0 \mu \mathrm{mol}$ of reducing sugar $\mathrm{min}^{-1}$ under the above conditions. Assays of immobilized TCWDE were done by replacing the TCWDE solution for $20 \mathrm{mg}$ of CGP/TCWDE. Blank reactions were performed in the presence of CGP activated by sodium periodate $(1 \mathrm{mmol}$ $\mathrm{L}^{-1}, 20 \mathrm{~min}$ ) in absence of enzyme.

\subsubsection{Chitinase Activity}

Chitinase activity was determined according to the methodology of Molano et al., (1977), using colloidal chitin prepared as described by Ralph Berger and Reynold, (1958). Assays were performed incubating 250 $\mu \mathrm{L}$ of colloidal chitin and $250 \mu \mathrm{L}$ of TCWDE solution at $37{ }^{\circ} \mathrm{C}$ for $2 \mathrm{~h}$, and the reducing sugar produced was determined by the method described by Miller (1959), using N-acetyl-D-glucosamine as standard. One unit of enzyme (U) was defined as the amount of enzyme necessary to produce $1.0 \mu \mathrm{mol}$ of reducing sugar in $2 \mathrm{~h}$ of reaction. Assays of immobilized TCWDE were done similarly, except the TCWDE solution was replaced by 10 $\mathrm{mg}$ of CGP/TCWDE. Blank reactions were performed in the presence of CGP activated by sodium periodate (1 $\mathrm{mmol} \mathrm{L}{ }^{-1}, 20 \mathrm{~min}$ ) in absence of enzymes.

\subsubsection{Protease Activity}

Protease activity was determined according to Arnon, (1970) using 1\% (w/v) casein solution as substrate. The reaction was performed for $20 \mathrm{~min}$, at $37^{\circ} \mathrm{C}$, and stopped by adding trichloroacetic acid. After centrifugation at $3300 \mathrm{~g}$, the supernatant was spectrophotometrically analyzed at $280 \mathrm{~nm}$. One enzyme unit (U) was defined as the amount of enzyme necessary to produce an increase of 0.1 in the optical density (OD). Assays of immobilized TCWDE were done similarly, except the TCWDE solution was replaced by $10 \mathrm{mg}$ of CGP/TCWDE. Blank reactions were performed in the presence of CGP activated by sodium periodate $\left(1 \mathrm{mmol} \mathrm{L}{ }^{-1}, 20 \mathrm{~min}\right)$ in absence of enzymes.

\subsection{Antifungal Activity of CGP/TCWDE}

The growth inhibitory activity of the CGP/TCWDE powder was determined by evaluating the growth of
Aspergillus fumigatus and Penicillium sp in the presence and absence of immobilized TCWDE. The CGP/TCWDE powder $(500 \mathrm{mg})$ was spread over PDA medium containing $80 \mu \mathrm{L}$ of spore's solution $\left(10^{7} \mathrm{~mL}^{-1}\right)$ of $A$. fumigatus or Penicillium sp. Inoculums were incubated at $37{ }^{\circ} \mathrm{C}$ for 96 hours. Growth inhibition was analyzed macroscopically by visual evaluation and microscopically by TEM (Transmission Electron Microscopy). TEM analysis was performed at $15 \mathrm{kV}$ (JEOL JEM-2100). Positive control was performed at the same experimental conditions in absence of CGP/TCWDE powder. Negative control was performed at the same experimental conditions replacing CGP/TCWDE by CGP.

\subsection{Storage stability of CGP/TCWDE}

CGP/TCWDE powder was stored at room temperature $\left(25^{\circ} \mathrm{C}\right)$ in airtight vials. NAGase activity was determined every 10 days in the first 100 days, and then every 50 days until complete 200 days of storage.

In order to verify if the inhibitory growth activity of CGP/TCWDE remained unchanged during a long storing time, inhibitory tests were conducted using CGP/TCWDE stored for 200 days at room temperature.

\subsection{Statistical analysis}

The results were expressed as mean \pm standard deviation $(\mathrm{X} \pm \mathrm{SD})$ of at least three determinations. Results from three-level factorial design $\left(3^{2}\right)$ were analyzed by using the software Statistica 7.0 (Statsoft, Inc., Tulsa, USA). The model was simplified by dropping terms that were not statistically significant $(p>0.05)$ by ANOVA.

\section{RESULTS AND DISCUSSION}

\subsection{Production of TCWDE}

Several factors influence CWDE production, including fungal specie and strain as well as the substrate used for enzyme induction. CWDE are frequently produced and secreted into the culture medium by a variety of fungi in response to the presence of chitin (Howell, 2003; Noronha and Ulhoa, 2000). As already shown in previous studies (Silva et al., 2011, 2012), T. asperellum (T00) produces substantial amounts of CWDE in culture media containing $0.5 \%(\mathrm{w} / \mathrm{v})$ chitin as carbon source, as can be seen in Table 2.

Table.2: TCWDE induced by T. asperellum after 6 days of incubation.

\begin{tabular}{ccc}
\hline Enzyme & $\begin{array}{c}\text { Enzymatic Activity } \\
\left(\mathbf{m U ~ m L}^{-\mathbf{1}}\right)\end{array}$ & $\begin{array}{c}\text { Specific Activity } \\
\left(\mathbf{m U ~ m}^{-1} \text { of protein }\right)\end{array}$ \\
\hline NAGase & $21370( \pm 2700)$ & $322240( \pm 9900)$ \\
Chitinase & $410( \pm 50)$ & $5610( \pm 750)$ \\
$\beta-1,3-$-Glucanase & $1460( \pm 80)$ & $20460( \pm 930)$ \\
Protease & $44( \pm 4,0)$ & $620( \pm 6,0)$ \\
\hline
\end{tabular}


It has been reported that chitinases, $\beta$-1,3-glucanases and NAGases produced by Trichoderma attack chitinaceous material in the cell wall, disrupting cell integrity and leading pathogens to death. Another well-known feature of $T$. asperellum is the differential production of CWDE as function of the compound used as inductor in the culture medium (Guigón-López et al., 2015; Mach et al., 1999; Zeilinger et al., 1999). In some cases, the use of raw materials such as commercial chitin may induce the production of proteases, since these raw materials frequently have some protein in their composition (Marcello et al., 2010).

Considering the high amount of NAGase produced by $T$. asperellum and the key role of this enzyme in the cell wall degradation (Lorito et al., 1996; Zeilinger et al., 1999), this enzyme was used as marker in the subsequent test of immobilization.

\subsection{TCWDE immobilization}

The use of oxidant agents such as sodium metaperiodate to produce reactivity points in the polysaccharide chain is widely known (Pappas et al., 2002). A scheme proposing a mechanism for the immobilization of TCWDE onto CGP is presented in Figure 1. In this proposed scheme, sodium metaperiodate acts on the hydroxyl groups at vicinal $\mathrm{C} 2$ and $\mathrm{C} 3$ in the main chain of CGP, leading to the appearing of reactive sites for enzyme binding. Basic amino acids such as lysine, arginine and histidine present at surface of the TCWDE would react with those oxidized sites of CGP. Moreover, the TCWDE have a high content of glycosylation, which are also susceptible to the oxidant action of sodium metaperiodate, significantly increasing the number of interaction points with CGP.
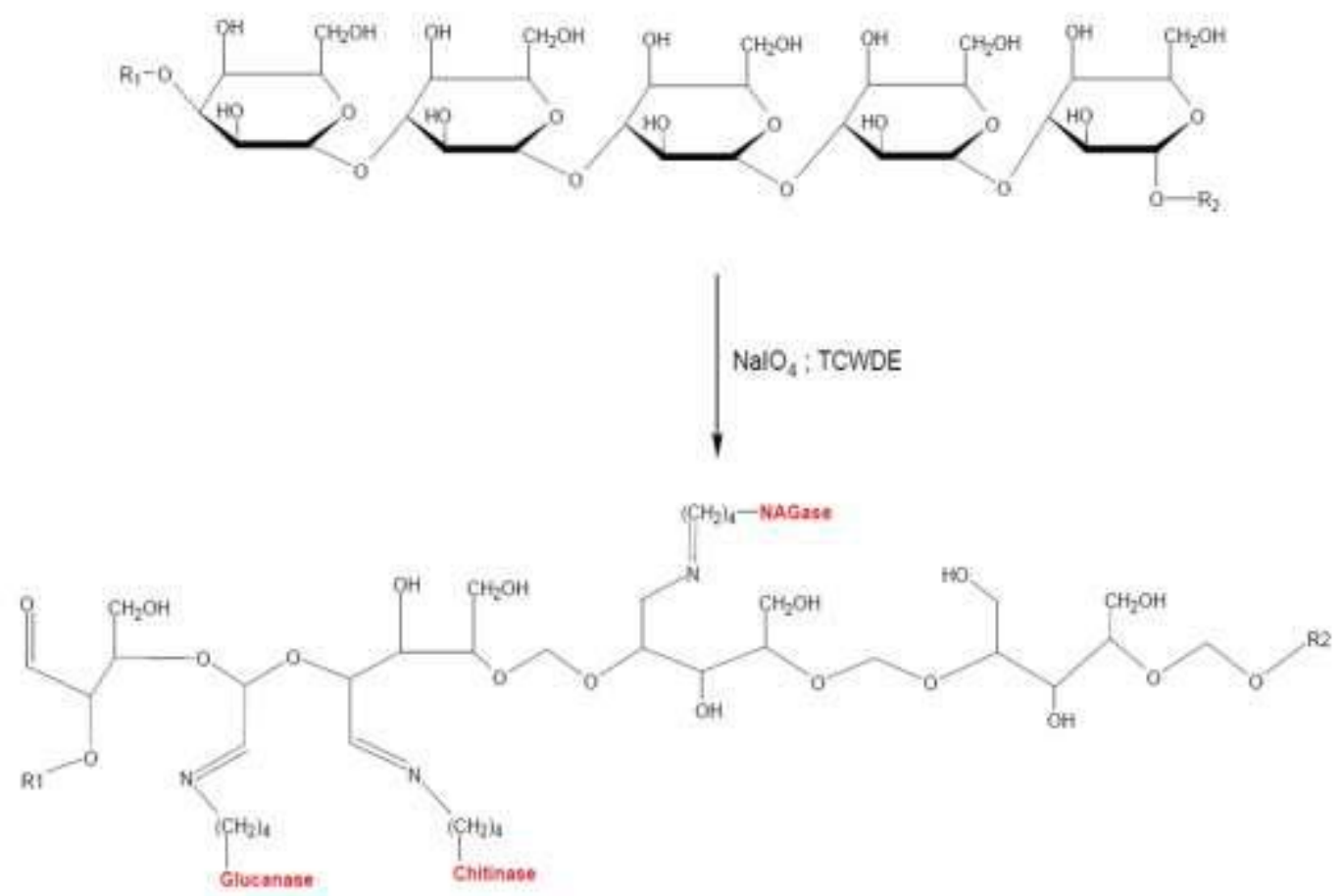

Fig.1: Scheme representing the reaction mechanism for TCWDE immobilization onto CGP.

A multivariate method was employed for the accurate determination of the individual and interaction effects related to the factors influencing the TCWDE immobilization. Optimization of metaperiodate $\left(\mathrm{NaIO}_{4}\right)$ concentration and immobilization time was achieved following a $3^{2}$-full factorial design, using as dependent variable the activity of NAGase retained in CGP.
The experimental design and results obtained from the experiments are shown in Table 1. As can be observed, the higher NAGase activity $\left(30.1 \mathrm{U} \mathrm{mL}^{-1}\right)$ was obtained by using $1.0 \mathrm{mmol} \mathrm{L}^{-1} \mathrm{NaIO}_{4}$ concentration and $20 \mathrm{~min}$ of immobilization time (run 1). On the other hand, the lowest NAGase activity $\left(6.4 \mathrm{U} \mathrm{mL}^{-1}\right)$ was observed with $10 \mathrm{mmol} \mathrm{L}^{-1} \mathrm{NaIO}_{4}$ concentration and $20 \mathrm{~min}$ of immobilization time (run 4). 
Table.1: Experimental design $\left(3^{2}\right)$ analyzing the effect $\mathrm{NaIO}_{4}$ concentration ( $\mathrm{mmol} \mathrm{L}^{-1}$ ) and immobilization time (min) on the NAGase activity immobilized onto CGP/TCWDE.

\begin{tabular}{cccc}
\hline & \multicolumn{2}{c}{ Variable level } & Response \\
\cline { 2 - 4 } Run & $\mathrm{NaIO}_{4}$ concentration & Immobilization time & NAGase activity \\
& $X_{1}$ & $X_{2}$ & $\left(\mathrm{U} \mathrm{mL}^{-1}\right)$ \\
\hline 1 & $1(-)$ & $20(-)$ & $30.1( \pm 0.38)$ \\
2 & $1(-)$ & $40(0)$ & $13.8( \pm 0.16)$ \\
3 & $1(-)$ & $60(+)$ & $18.8( \pm 0.15)$ \\
4 & $10(0)$ & $20(-)$ & $6.4( \pm 0.14)$ \\
5 & $10(0)$ & $40(0)$ & $20.1( \pm 0,04)$ \\
6 & $10(0)$ & $60(+)$ & $10.1( \pm 0.84)$ \\
7 & $100(+)$ & $20(-)$ & $23.6( \pm 0.02)$ \\
8 & $100(+)$ & $40(0)$ & $8.6( \pm 0.48)$ \\
9 & $100(+)$ & $60(+)$ & $15.6( \pm 0.08)$ \\
\hline
\end{tabular}

Results from statistical analysis indicated an adequate fit of experimental values to the proposed model $\left(r^{2}=0.99\right)$, which means that this factorial design $\left(3^{2}\right)$ is accurately able to represent the relationships between the independent variables (factors) and NAGase activity (dependent variable). Figure 2 shows the graphical representation (Pareto chart) of the magnitude of each of the parameters investigated upon NAGase activity. As can be seen, except for the factor interaction between the linear terms of $\mathrm{NaIO}_{4}$ concentration and immobilization time $\left(X_{1} X_{2}\right)$, all the other factors significantly affected the response $(\mathrm{p}=0.05)$. The results from multivariate analysis also showed that all interaction factors positively affected the NAGase activity, and the factor interaction between the quadratic terms $X_{1}^{2} X_{2}^{2}$ had the most pronounced effect (49.64) on this response. On the other hand, the linear and quadratic terms of $\mathrm{NaIO}_{4}$ concentration and immobilization time negatively affected the activity of the immobilized NAGase.

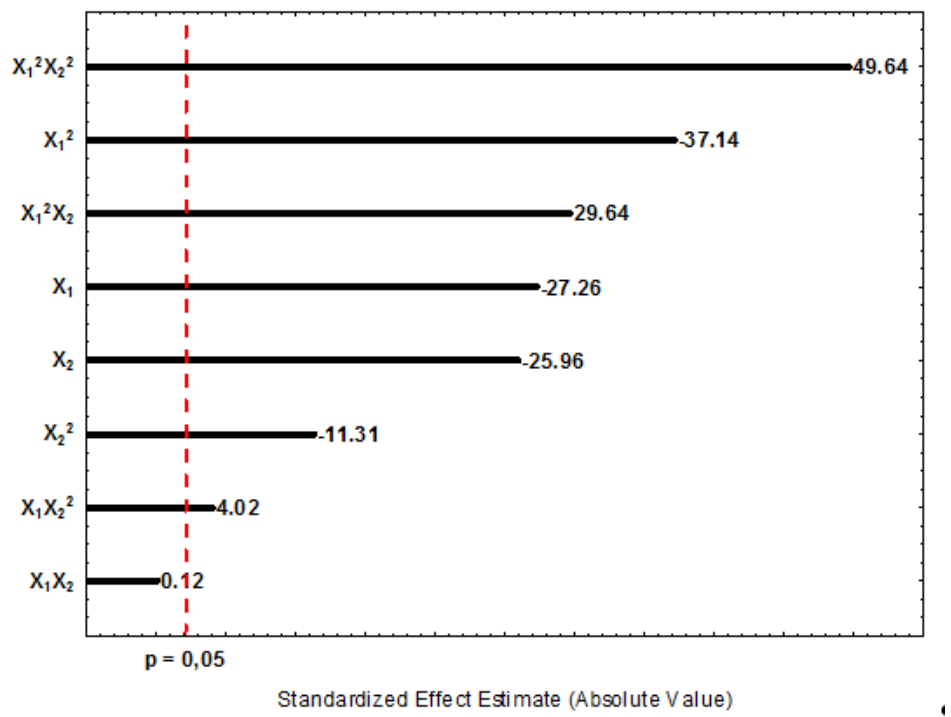

Fig.2: Pareto Chart for NAGase activity as function of $\mathrm{NaIO}_{4}$ concentration and immobilization time.

The negative effect showed by $\mathrm{NaIO}_{4}$ concentration can be explained due to the oxidant action of this reagent over the polysaccharide chain. Increasing the concentration of $\mathrm{NaIO}_{4}$ may produce an excess of binding points, which could lead to formation of interchain bonds, crosslinking the polysaccharide chain. The crosslinking of CGP chain will restrict the available points for enzyme binding. In fact, when immobilization is conducted by treating CGP with $\mathrm{NaIO}_{4}$ prior to the addition of TCWDE, CGP precipitates and immobilization does not occur (data not shown). Similarly, the negative effect observed by increasing the immobilization time is probably due to the prolonged oxidative action of $\mathrm{NaIO}_{4}$ on both CGP and TCWDE.

At the best conditions for NAGase immobilization the amounts of TCWDE immobilized onto CGP are shown at Table 3. 
Table.3: Enzymatic activity and percentage of retention on TCWDE on to CGP.

\begin{tabular}{lcc}
\hline & $\begin{array}{c}\text { Enzymatic activity of CGP/TCWDE (U } \\
\left.\mathrm{mL}^{-1}\right)\end{array}$ & Retention (\%) \\
\hline NAGase & $30.1( \pm 0.38)$ & 93 \\
Chitinase & $0.67( \pm 0.05)$ & 41 \\
$\beta-1,3$-glucanase & $0.017( \pm 0.001)$ & 24 \\
Protease & $\ldots$ & $\cdots$ \\
\hline
\end{tabular}

The percentage of retention was calculated as the amount of enzyme units offered that were immobilized onto CGP. Differences observed in the immobilization efficiency may be ascribed to intrinsic differences of the enzyme structures and amino acids composition. The immobilization onto CGP activated by reaction with $\mathrm{NaIO}_{4}$ predominantly occurs through the basic amino acids lysine, arginine and histidine, and in a minor frequency, through glycosylation sites at enzyme molecule, which can be oxidized and became reactive for CGP (acetal linkage). Therefore, the availability of these binding sites at surface of the enzyme molecule will directly influence the intrinsic retention yield.

\subsection{Antifungal Activity of CGP/TCWDE}

Some fungi are plant pathogens and start the spoilage in the field whereas others just proliferate and cause substantial spoilage only after harvest, when the main plant defenses are reduced or eliminated (Tournas and Katsoudas, 2005).

The inhibitory effect of CGP/TCWDE was tested against A. fumigatus and Penicillium sp., which present great importance due to their ability to produce mycotoxins (Clemmensen et al., 2007; Latgé, 2001) and the frequency in which they appear as fresh food contaminant (Tournas and Katsoudas, 2005).

Figure 3 depicts the inhibitory effect of CGP/TCWDE on the growth of Aspergillus fumigatus (Figure $3-\mathrm{A}, \mathrm{B}$ and C) and Penicillium sp. (Figure $3-\mathrm{D}, \mathrm{E}$ and F). CGP/TCWDE was very effective in the inhibition of $A$. fumigatus growth, as shown in Figure $3 \mathrm{~B}$, and inhibited the growth of Penicillium sp. in a less extension, after 96 $\mathrm{h}$ of incubation. The differences in the inhibitory activity of CGP/TCWDE against the tested fungi is probably related to variances in the composition of the cell wall of these microorganisms, which conferred different susceptibility to the hydrolytic action of the TCWDE (Silva et al., 2011). Moreover, the main constituents of the fungal cell wall - polysaccharides (chitin and $\alpha$ - and $\beta$ glucans), proteins, and lipids - may be differently distributed across the cell walls of A. fumigatus and Penicillium sp., (Hearn et al., 1998; Pinto et al., 2008), producing different hydrolysis susceptibility.

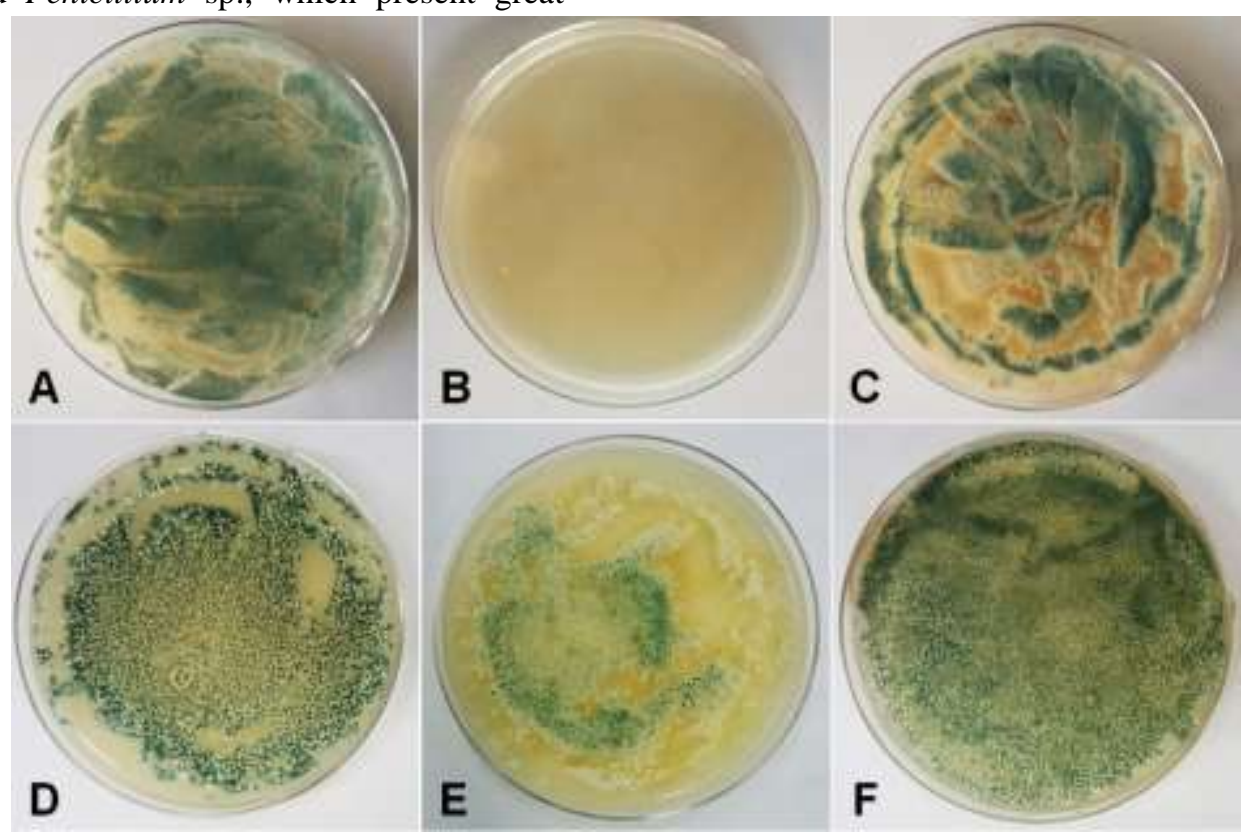

Fig.3: Fungal growth inhibition after $96 \mathrm{~h}:$ A) A. fumigatus; B) A. fumigatus + CGP/TCWDE; C) A. fumigatus + CGP; D) Penicillium sp.; E) Penicillium sp. + CGP/TCWDE and F) Penicillium sp. + CGP. 
TEM micrographs reinforced and evidenced the action of the CGP/TCWDE as growth inhibitor agent (Figure 4). Considering the effect of CGP/TCWDE on the growth of A. fumigatus, the comparison between control tests (Figure $4-\mathrm{A}$ ) and that using CGP/TCWDE (Figure 4 B) evidenced remarkable changes in the form, organization and electronic density of the cell wall structure. Interestingly, the CGP alone also caused some changes in the cell wall (Figure $4-\mathrm{C}$ ), which was probably due to the high-water absorption capacity of this polysaccharide, resulting in some dehydration and damage to the cell wall structure.

Similar result was observed for Penicillium sp. (Figure 4 -

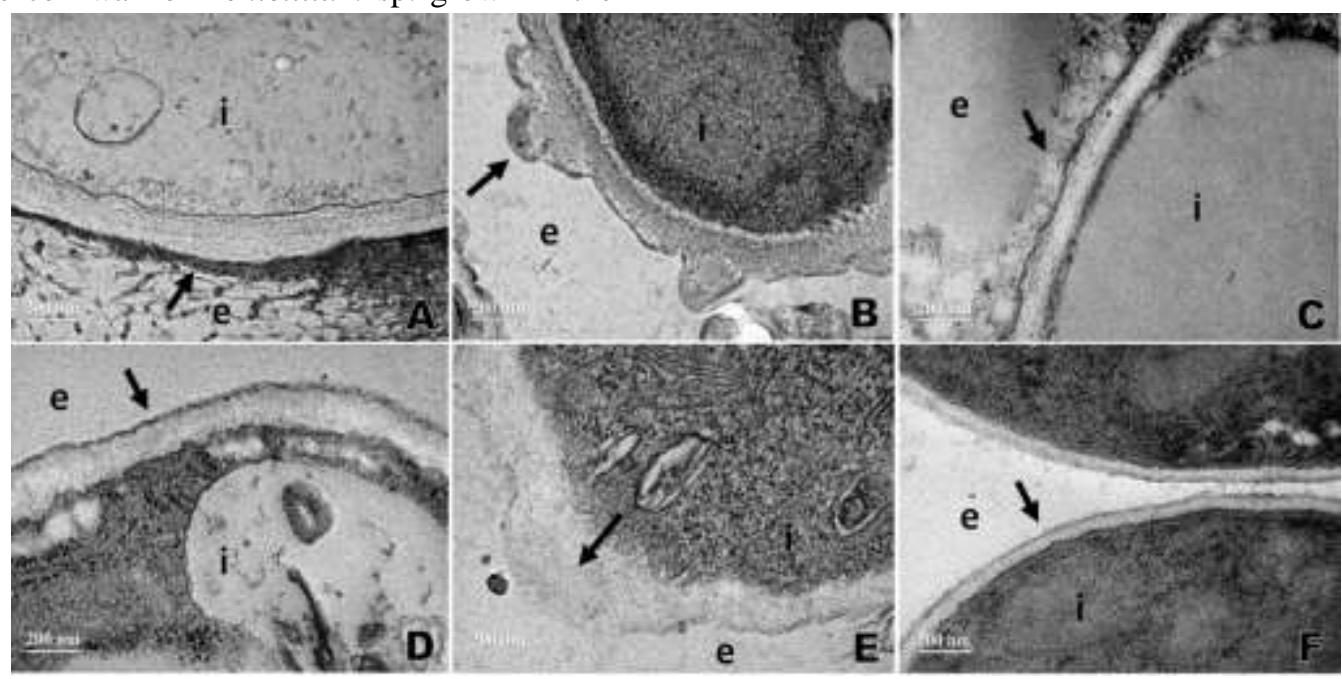

Fig.4: Transmission Electronic Microscopy: A) A. fumigatus; B) A. fumigatus + CGP/TCWDE; C) A. fumigatus + CGP; D) Penicillium sp.; E) Penicillium sp. + CGP/TCWDE and F) Penicillium sp. + CGP.

\subsection{Storage stability of CGP/TCWDE}

The stability of a preparation containing immobilized enzymes is an important parameter, which can determine the economic viability of any food additive (Fernandes, 2010). The shelf life of CGP/TCWDE was tested during 200 days (Figure 5). As can be seen, there was a decreasing of $49.6 \%$ of the initial activity after 40 days stored in a dry state, at room temperature. After that, no further loss in activity was detected until 200 days of storage. This is a highly significant result since the recovery of activity following the drying process of several immobilized enzymes is reportedly very low (Fernandes et al., 2004; Purcena et al., 2009; Soares et al., 2002; Wu et al., 2007).

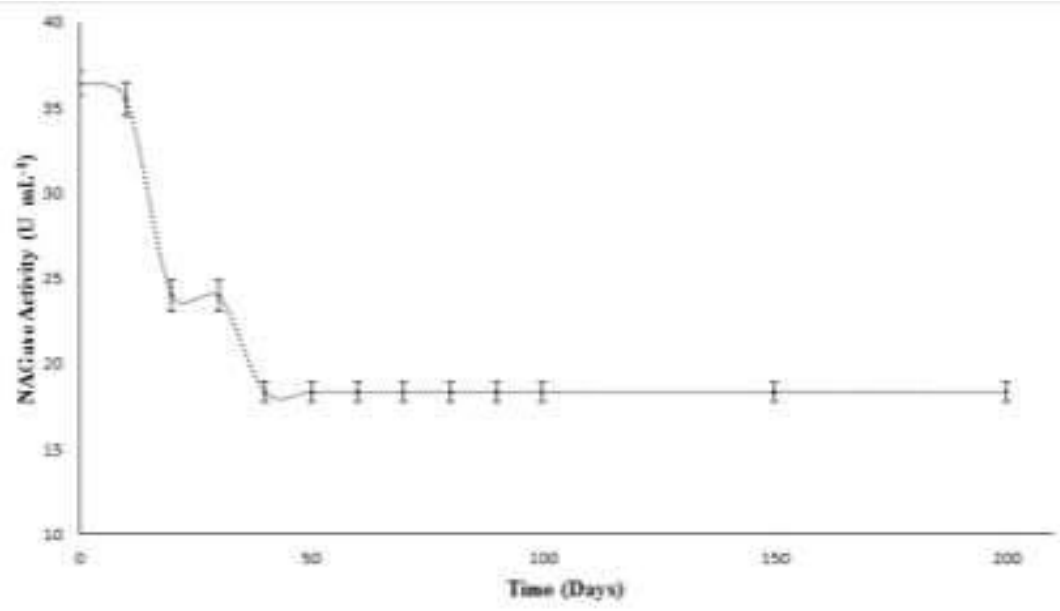

Fig.5: Storage stability of CGP/TCWDE. 
The decrease in the activity of CGP/TCWDE powder probably occurred during drying procedure, when the evaporation of water molecules induced rearrangements of the polypeptide chains. These rearrangements may occur in different patterns for TCWD enzymes as function of the specific amino acids composition, protein structure and surrounding environment. In this case, when rehydrated, some molecules did not recover their original tridimensional structure, and hence, did not recover their hydrolytic activity. It appears that immobilization restrains the motility of the protein side chains that are

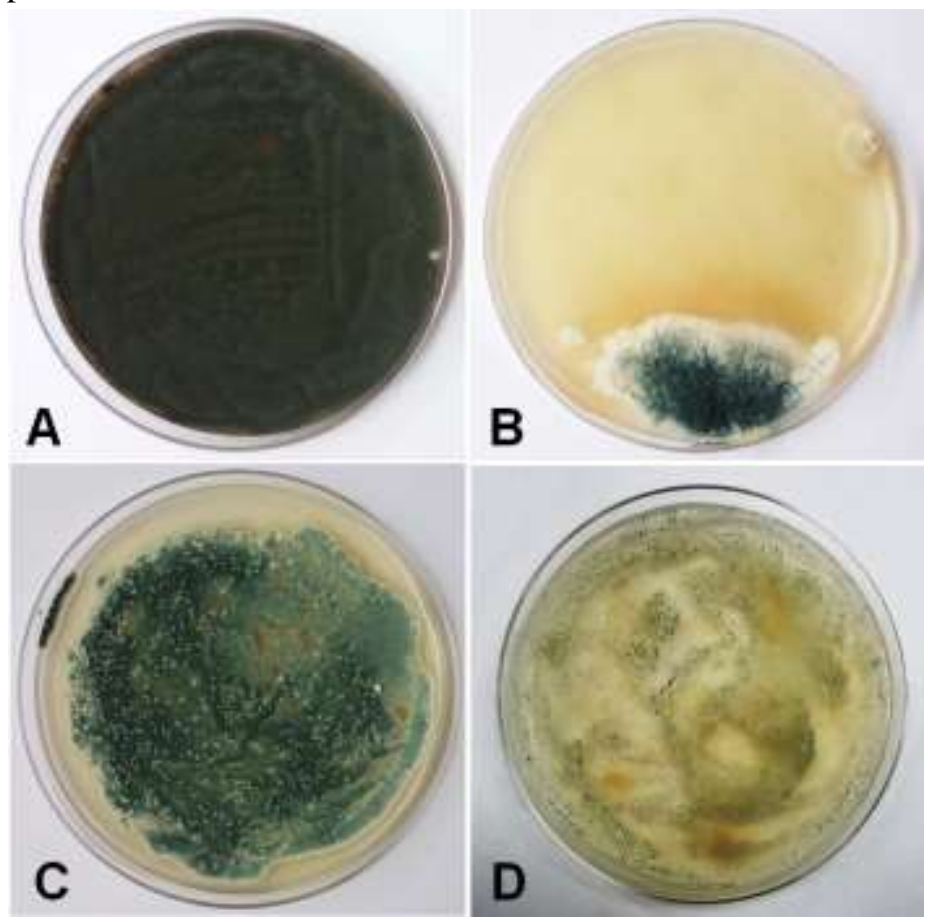

Fig.6: Fungal growth inhibition after 200 days of storage at room temperature: A) A. fumigatus; B) A. fumigatus + CGP/TCWDE; C) Penicillium sp.; D) Penicillium sp. + CGP/TCWDE.
The efficiency of the fungal growth inhibition combined to the high storage stability of CGP/TCWDE makes this material a very promising product for improvement of shelf life of fresh foods. The CGP/TCWDE is a watersoluble powder which is produced by combining two lowcost products: the CGP, an edible byproduct from cashew cultivation, and the TCWDE, which are produced in high yield by a bioprocess using chitin, as a cheap carbon source. Combining CGP with TCWDE resulted in a harmless, water-soluble, biodegradable and cost-effective product, therefore presenting characteristics to attend the consumer concerns and to be very promising to reach the market.

\section{CONCLUSIONS}

The use of TCWDE as control agent of fungal spoilage in fresh foods was shown to be very promising. The immobilization of TCWDE onto CGP conferred to TCWDE high stability during storage and resulted in a necessary to adapt the molecule to a dehydrated environment, and this can lead to a considerable loss of activity. In the case of CGP/TCWDE, the observed recovery of activity from dried samples suggests that long-term storage during transport, for example, would not be a problem.

Finally, the stability of CGP/TCWDE stored for 200 days at room temperature was confirmed by the inhibitory activity on the growth of A. fumigatus and Penicillium sp., as showed in Figure 6.

\section{B}

formulation of easily use during food processing or packaging. CGP/TCWDE was very effective to inhibit the growth of A. fumigatus and Penicillium sp. in a mechanism that involves changes in the cell wall of those microorganisms. The use of CGP/TCWDE in active packaging devices could be a natural alternative to avoid the growth of fungi in different food products in substitution of common commercial preservatives.

Additionally, CGP/TCWDE in a water-soluble powder formulation present the advantage of a close contact between the active component (enzymes) and the contaminated food, making easier the release of the enzyme to actuate on the microorganism wall. Moreover, the high water solubility of CGP/TCWDE makes ease to remove this bioactive component from foods during washing and assure the ingestion of a food free of contaminants. 


\section{ACKNOWLEDGEMENTS}

This study was supported by a grant provided by $\mathrm{CNPq}$ (Process number 402468/2013 9). Maurício V. Cruz thanks FAPEG for the fellowship support. Karla A. Batista and Marcos A. Pereira Junior thank CAPES for the fellowship support.

\section{REFERENCES}

[1] Arnon, R., 1970. Papain. Methods in Enzymology $19,226$.

[2] Clemmensen, L.H., Hansen, M.E., Frisvad, J.C., Ersbøll, B.K., 2007. A method for comparison of growth media in objective identification of Penicillium based on multi-spectral imaging. J. Microbiol. Methods 69, 249-255. doi:10.1016/j.mimet.2006.12.020

[3] FAO, 2011. Global food losses and food wasre Extent, causes and preservation. Rome.

[4] FAO, IFAD, WFP, 2014. The State of food insecurity in the world 2014. Rome.

[5] Fernandes, K.F., Lima, C.S., Lopes, F.M., Collins, C.H., 2004. Properties of horseradish peroxidase immobilised onto polyaniline. Process Biochem. 39, 957-962. doi:10.1016/S0032-9592(03)00211-5

[6] Fernandes, P., 2010. Enzymes in Food Processing: A Condensed Overview on Strategies for Better Biocatalysts. Enzyme Res. 2010, e862537. doi:10.4061/2010/862537

[7] Grace, D., 2015. Food Safety in Low and Middle Income Countries. Int. J. Environ. Res. Public. Health 12, 10490-10507. doi:10.3390/ijerph120910490

[8] Guigón-López, C., Vargas-Albores, F., GuerreroPrieto, V., Ruocco, M., Lorito, M., 2015. Changes in Trichoderma asperellum enzyme expression during parasitism of the cotton root rot pathogen Phymatotrichopsis omnivora. Fungal Biol. 119, 264-273. doi:10.1016/j.funbio.2014.12.013

[9] Hearn, V.M., Escott, G.M., Glyn, E., Evans, V., Adams, D.J., 1998. Complex chitinolytic system of Aspergillus fumigatus. Microbios 93, 85-104.

[10] Howell, C.R., 2003. Mechanisms Employed by Trichoderma Species in the Biological Control of Plant Diseases: The History and Evolution of Current Concepts. Plant Dis. 87, 4-10. doi:10.1094/PDIS.2003.87.1.4

[11] Jedermann, R., Nicometo, M., Uysal, I., Lang, W., 2014. Reducing food losses by intelligent food logistics. Philos. Transact. A Math. Phys. Eng. Sci. 372. doi:10.1098/rsta.2013.0302

[12] Koizumi, T., 2015. Biofuels and food security. Renew. Sustain. Energy Rev. 52, 829-841.
[13] Latgé, J.P., 2001. The pathobiology of Aspergillus fumigatus. Trends Microbiol. 9, 382-389.

[14]López de Lacey, A.M., López-Caballero, M.E., Gómez-Estaca, J., Gómez-Guillén, M.C., Montero, P., 2012. Functionality of Lactobacillus acidophilus and Bifidobacterium bifidum incorporated to edible coatings and films. Innov. Food Sci. Emerg. Technol. 16, 277-282. doi:10.1016/j.ifset.2012.07.001

[15]Lopez-Rubio, A., Gavara, R., Lagaron, J.M., 2006. Bioactive packaging: turning foods into healthier foods through biomaterials. Trends Food Sci. Technol. 17, 567-575. doi:10.1016/j.tifs.2006.04.012

[16]Lorito, M., Mach, R.L., Sposato, P., Strauss, J., Peterbauer, C.K., Kubicek, C.P., 1996. Mycoparasitic interaction relieves binding of the Cre1 carbon catabolite repressor protein to promoter sequences of the ech42 (endochitinase-encoding) gene in Trichoderma harzianum. Proc. Natl. Acad. Sci. U. S. A. $93,14868-14872$.

[17] Mach, R.L., Peterbauer, C.K., Payer, K., Jaksits, S., Woo, S.L., Zeilinger, S., Kullnig, C.M., Lorito, M., Kubicek, C.P., 1999. Expression of Two Major Chitinase Genes of Trichoderma atroviride ( $T$. harzianum P1) Is Triggered by Different Regulatory Signals. Appl. Environ. Microbiol. 65, 1858-1863.

[18] Marcello, C.M., Steindorff, A.S., da Silva, S.P., Silva, R. do N., Mendes Bataus, L.A., Ulhoa, C.J., 2010. Expression analysis of the exo-beta-1,3glucanase from the mycoparasitic fungus Trichoderma asperellum. Microbiol. Res. 165, 7581. doi:10.1016/j.micres.2008.08.002

[19] Marques, M.R., Albuquerque, L.M.B., Xavier-Filho, J., 1992. Antimicrobial and insecticidal activities of cashew tree gum exudate. Ann. Appl. Biol. 121, 371-377. doi:10.1111/j.1744-7348.1992.tb03450.x

[20] Miller, G.L., 1959. Use of Dinitrosalicylic Acid Reagent for Determination of Reducing Sugar. Anaytical Chemistry 31, 426-428.

[21] Min, S.C., Roh, S.H., Niemira, B.A., Boyd, G., Sites, J.E., Uknalis, J., Fan, X., 2017. In-package inhibition of E. coli O157:H7 on bulk Romaine lettuce using cold plasma. Food Microbiol. 65, 1-6. doi:10.1016/j.fm.2017.01.010

[22] Molano, J., Durán, A., Cabib, E., 1977. A rapid and sensitive assay for chitinase using tritiated chitin. Anal. Biochem. 83, 648-656. doi:10.1016/00032697(77)90069-0

[23] Moreira, B.R., Batista, K.A., Castro, E.G., Lima, E.M., Fernandes, K.F., 2015. A bioactive film based on cashew gum polysaccharide for wound dressing 
applications. Carbohydr. Polym. 122, 69-76. doi:10.1016/j.carbpol.2014.12.067

[24] Noronha, E.F., Ulhoa, C.J., 2000. Characterization of a 29-kDa beta-1,3-glucanase from Trichoderma harzianum. FEMS Microbiol. Lett. 183, 119-123.

[25] Olmedo, G.M., Cerioni, L., González, M.M., Cabrerizo, F.M., Rapisarda, V.A., Volentini, S.I., 2017. Antifungal activity of $\beta$-carbolines on Penicillium digitatum and Botrytis cinerea. Food Microbiol. 62, 9-14. doi:10.1016/j.fm.2016.09.011

[26] Pappas, A.C., Stalikas, C.D., Fiamegos, Y.C., Karayannis, M.I., 2002. Determination of hydrogen peroxide by using a flow injection system with immobilized peroxidase and long pathlength capillary spectrophotometry. Anal. Chim. Acta 455, 305-313. doi:10.1016/S0003-2670(01)01600-2

[27]Pinto, M.R., Barreto-Bergter, E., Taborda, C.P., 2008. Glycoconjugates and polysaccharides of fungal cell wall and activation of immune system. Braz. J. Microbiol. Publ. Braz. Soc. Microbiol. 39, 195-208. doi:10.1590/S1517-83822008000200001

[28] Purcena, L.L.A., Caramori, S.S., Mitidieri, S., Fernandes, K.F., 2009. The immobilization of trypsin onto polyaniline for protein digestion. Mater. Sci. Eng. C 29, 1077-1081. doi:10.1016/j.msec.2008.09.014

[29] Quelemes, P.V., Araruna, F.B., de Faria, B.E.F., Kuckelhaus, S.A.S., da Silva, D.A., Mendonça, R.Z., Eiras, C., dos S. Soares, M.J., Leite, J.R.S.A., 2013. Development and Antibacterial Activity of Cashew Gum-Based Silver Nanoparticles. Int. J. Mol. Sci. 14, 4969-4981. doi:10.3390/ijms14034969

[30] Ralph Berger, L., Reynold, D.M., 1958. The chitinase system of a strain of Streptomyces Griseus. Biochim. Biophys. Acta 29, 522-534. doi:10.1016/0006-3002(58)90008-8

[31] Rembiałkowska, E., 2007. Quality of plant products from organic agriculture. J. Sci. Food Agric. 87, 2757-2762. doi:10.1002/jsfa.3000

[32] Shafie, F.A., Rennie, D., 2012. Consumer Perceptions Towards Organic Food. Procedia - Soc. Behav. Sci., Proceedings of the 1st National Conference on Environment-Behaviour Studies, 1nCEBS, FAPS, UiTM, Shah Alam, Malaysia, 1415 November, 2009 49, 360-367. doi:10.1016/j.sbspro.2012.07.034

[33] Silva, B.D.S., Ulhoa, C.J., Batista, K.A., Di Medeiros, M.C., Filho, R.R. da S., Yamashita, F., Fernandes, K.F., 2012. Biodegradable and bioactive CGP/PVA film for fungal growth inhibition. Carbohydr. Polym. 89, 964-970. doi:10.1016/j.carbpol.2012.04.052
[34] Silva, B.D.S., Ulhoa, C.J., Batista, K.A., Yamashita, F., Fernandes, K.F., 2011. Potential fungal inhibition by immobilized hydrolytic enzymes from Trichoderma asperellum. J. Agric. Food Chem. 59, 8148-8154. doi:10.1021/jf2009815

[35] Silva, F.E.F., Batista, K.A., Di-Medeiros, M.C.B., Silva, C.N.S., Moreira, B.R., Fernandes, K.F., 2016. A stimuli-responsive and bioactive film based on blended polyvinyl alcohol and cashew gum polysaccharide. Mater. Sci. Eng. C Mater. Biol. Appl. 58, 927-934. doi:10.1016/j.msec.2015.09.064

[36] Silva, T.M., Santiago, P.O., Purcena, L.L.A., Fernandes, K.F., 2010. Study of the cashew gum polysaccharide for the horseradish peroxidase immobilization - Structural characteristics, stability and recovery. Mater. Sci. Eng. C 30, 526-530. doi:10.1016/j.msec.2010.01.016

[37] Soares, A.L., Guimarães, G.M., Polakiewicz, B., de Moraes Pitombo, R.N., Abrahão-Neto, J., 2002. Effects of polyethylene glycol attachment on physicochemical and biological stability of E. coli L-asparaginase. Int. J. Pharm. 237, 163-170.

[38] Tournas, V.H., Katsoudas, E., 2005. Mould and yeast flora in fresh berries, grapes and citrus fruits. Int. J. Food Microbiol. 105, 11-17. doi:10.1016/j.ijfoodmicro.2005.05.002

[39] Wu, J.C., Lee, S.S., Mahmood, M.M.B., Chow, Y., Talukder, M.M.R., Choi, W.J., 2007. Enhanced activity and stability of immobilized lipases by treatment with polar solvents prior to lyophilization. J. Mol. Catal. B Enzym. 45, 108-112. doi:10.1016/j.molcatb.2007.01.003

[40] Yabuki, M., Mizushina, K., Amatatsu, T., Ando, A., Fujii, T., Shimada, M., Yamashita, M., 1986. PURIFICATION AND CHARACTERIZATION OF CHITINASE AND CHITOBIASE PRODUCED BY AEROMONAS HYDROPHILA SUBSP. ANAEROGENES A52. J. Gen. Appl. Microbiol. 32, 25-38. doi:10.2323/jgam.32.25

[41]Zeilinger, S., Galhaup, C., Payer, K., Woo, S.L., Mach, R.L., Fekete, C., Lorito, M., Kubicek, C.P., 1999. Chitinase Gene Expression during Mycoparasitic Interaction of Trichoderma harzianumwith Its Host. Fungal Genet. Biol. 26, 131-140. doi:10.1006/fgbi.1998.1111 